Reseña de Abipones en las fronteras del Chaco. Una etnografía histórica sobre el siglo XVIII, de Carina Lucaioli. $1^{\text {a }}$ Edición, Buenos Aires: Sociedad Argentina de Antropología, 2011, 352 pp. (Colección Tesis Doctorales)

\title{
Judith Farberman
}

\section{OpenEdition}

Journals

\section{Electronic version}

URL: http://journals.openedition.org/corpusarchivos/1018

DOI: 10.4000/corpusarchivos.1018

ISSN: 1853-8037

\section{Publisher}

Diego Escolar

\section{Electronic reference}

Judith Farberman, «Reseña de Abipones en las fronteras del Chaco. Una etnografía histórica sobre el siglo XVIII, de Carina Lucaioli. $7^{\text {a }}$ Edición, Buenos Aires: Sociedad Argentina de Antropología, 2011, 352 pp. (Colección Tesis Doctorales) », Corpus [En línea], Vol 2, No 1 | 2012, Publicado el 30 junio 2012, consultado el 07 mayo 2019. URL : http://journals.openedition.org/corpusarchivos/1018; DOI 10.4000/corpusarchivos.1018

This text was automatically generated on 7 May 2019. 


\title{
Reseña de Abipones en las fronteras del Chaco. Una etnografía histórica sobre el siglo XVIII, de Carina Lucaioli. $1^{\text {a }}$ Edición, Buenos Aires: Sociedad Argentina de Antropología, 2011, 352 pp. (Colección Tesis Doctorales)
}

\author{
Judith Farberman
}

1 El libro de Carina Lucaioli es el resultado de su tesis doctoral y representa la continuidad de una primera investigación publicada en 2005. Además de profundizar ciertas cuestiones ya tratadas en aquel primer trabajo y de basarse en un corpus documental mucho más amplio, se integran aquí temas nuevos, se avanza en la formulación de hipótesis más abarcativas y audaces y en la sistematización de los aportes. Para decirlo en pocas palabras, nos encontramos frente a un libro de historia escrito por una antropóloga, que enfoca las relaciones coloniales desde las fronteras, poniendo en primer plano a las sociedades indígenas soberanas del Chaco.

2 Abipones en la frontera del Chaco es un libro de historia porque los procesos de cambio están en el centro de las preocupaciones de la autora: todo un desafío tratándose de sociedades durante mucho tiempo percibidas por la literatura académica como inmóviles y casi prisioneras de sus sistemas culturales. Y es también un libro de antropología por el enfoque que preside la lectura de las fuentes textuales y la permanente puesta a prueba de modelos teóricos. Es un buen ejemplo de construcción interdisciplinaria, evidente también en la recuperación, la reseña y la crítica de la literatura histórica y antropológica existente.

3 El período abarcado por este estudio (1700-1767) es breve pero intenso y está delimitado por dos momentos muy significativos en la historia de las relaciones interétnicas. En efecto, hacia 1700 indígenas y colonos ya no pueden ignorarse mutuamente: tras alcanzar 
su máxima expansión territorial, los abipones comenzarán a presionar sobre el territorio fronterizo. El año 1767 es una fecha más convencional y obedece a la crisis de las reducciones tras la expulsión de los jesuitas, que promueve nuevos reacomodamientos en el interior del Chaco. Un parte aguas en estos setenta años lo conforma la solicitud de reducciones por parte de los abipones y su puesta en marcha entre 1748 y 1764. Sin imponerse como una tregua generalizada, la fundación de reducciones tenderá a atenuar los ataques indígenas de más vasto alcance, amplificará el menú de opciones para los grupos abipones y complejizará el armado de las relaciones intraétnicas.

4 La hipótesis general que rige la investigación propone que los cambios que acompañaron las diversas formas de interacción entre abipones e hispanocriollos no condujeron a la desestructuración de la sociedad indígena, sino todo lo contrario. En este sentido, Lucaioli apunta, sobre todo, a las respuestas creativas desarrolladas por los abipones, capaces de incorporar eficazmente los dispositivos coloniales (en particular las reducciones) a su reproducción social, en buena medida gracias a la versatilidad de sus estructuras políticas. Así las cosas, en el complejo juego de los actores fronterizos, la relación de fuerzas habría favorecido en líneas generales a los indígenas, que contaban con otro plus: la posibilidad siempre a mano de refugiarse en las profundidades de un territorio del que no abandonaron el señorío, incluso después de la etapa reduccional.

Pero el texto de Lucaioli se abre hacia un análisis mucho más fino y pormenorizado que el reseñado hasta aquí. Un mérito del libro es, justamente, la identificación de una diversidad de actores fronterizos, con intereses no siempre coincidentes. La sociedad hispano criolla no era un bloque: contenía a misioneros, funcionarios coloniales de diverso rango, vecinos, milicianos y campesinos de tres gobernaciones diferentes, todos ellos involucrados más o menos directamente(las más de las veces como víctimas, pero eventualmente también como beneficiarios) en las políticas y acciones fronterizas. Del otro lado, el rótulo "abipones" encubría a múltiples grupos de entidad demográfica variable, organizados en estructuras políticas demasiado laxas para facilitar el diálogo con los representantes coloniales y con otros grupos indígenas.

¿Es esta dispersión de actores la que vuelve incomprensible la sucesión de conflictos y paces sin fin que, por ejemplo, se desprende de la lectura de las actas capitulares de las ciudades limítrofes con el Chaco? En realidad, este libro ofrece algunas pistas y orientaciones que volverían menos fortuitas estas secuencias. Al mirar desde "adentro" de la frontera y no desde cada cabecera colonial por separado, Lucaioli consigue construir ciertas lógicas de funcionamiento. Sin ir más lejos, que la paz con una ciudad (Santa Fe en los años 30, por ejemplo) podía costarles a otras (Santiago del Estero, Asunción, Córdoba) la destrucción y el saqueo. Y que esas historias previas, en las que las relaciones institucionales se mezclaban con las personales que por décadas unieron a indígenas y colonos, condicionaron posteriormente la erección de las reducciones jesuíticas.

\section{Los caciques, la guerra y la paz}

7 Para explorar los sistemas de autoridad indígena y el papel de la guerra -problemas clásicos de la antropología política y económica-, Lucaioli acude a modelos teóricos que pone a prueba con rigurosidad. Una y otra cuestión van asociadas y conforman una clave de lectura del texto: la autonomía de los abipones es perdurable y, en buena medida, se sostiene gracias a la flexibilidad de cacicazgos necesitados de una permanente 
construcción de consensos. La guerra, además de la habilidad diplomática, aparece como una de las grandes canteras de estos liderazgos.

Como es sabido, no son estos temas nuevos en la literatura sobre el Chaco, y Lucaioli se encarga de reseñar y discutir los aportes de la literatura histórica y etnográfica más y menos recientes. Se ha hipotetizado, por ejemplo, acerca de una nueva preeminencia de los líderes guerreros por sobre aquellos hereditarios en el contexto colonial (Susnik 1981), o sobre el tránsito del cacicazgo a la jefatura a partir de la existencia de relaciones más estrechas y estables con las ciudades (Vitar 2003, Paz 2005). Sin embargo, la hipótesis de la autora abreva sobre todo en los estudios desarrollados para otras regiones. Sobresalen entre ellos los debidos a Bechis ([1989]; 2008) sobre el ejercicio del poder y la autoridad, a Nacuzzi (1998) sobre las jefaturas duales o compartidas entre los pampas, los de Boccara (1998) sobre el papel de los conas entre los reche, y los de Saignes (1990) sobre los caciques chiriguanos. Todos ellos comparten la identificación de una cierta "división del trabajo" entre los líderes étnicos, basada no tanto en su carácter hereditario o adquirido sino en las funciones que desempeñaban. De esta suerte, y partiendo de la idea de que las fuentes tienden a aplanar la complejidad de los sistemas políticos indígenas, la autora afirma el surgimiento de liderazgos que superaban los límites de la banda, pero que no eran los auspiciados por los funcionarios o misioneros, ni los más visibles en las fuentes textuales. En buena medida, la intermitencia de los ataques abipones -leída como deslealtad por los agentes coloniales- también es asociada a la inestabilidad de sus liderazgos o, desde otro lugar, a la libertad de los seguidores de un cacique para abandonarlo en caso de no satisfacer sus expectativas.

9 La guerra es para Lucaioli una estructura de la sociedad abipona, anterior a su historia colonial y elemento fundamental en la construcción de la identidad grupal. Sin embargo, no por ello constituiría una esencia del grupo, como la concebían los cronistas ignacianos y algunos historiadores y antropólogos también. Como se examina en el libro, no solo la adopción del caballo cambió las modalidades de esta guerra. En rigor, la posibilidad de amplificar los circuitos de intercambio ya existentes -y que la fundación de reducciones multiplica- desaconsejó ciertas estrategias guerreras (el malón) pero sin implicar el abandono de otras (el asalto). Las reducciones no entrañaron una pérdida de la autonomía pero sí colocaron a algunos caciques en una situación más comprometida, restándole posibilidades a las empresas guerreras que requerían de mayor organización. En cualquier caso, la guerra indígena tenía su espejo en la hispano- criolla y es un acierto que se analicen conjuntamente malones y entradas punitivas. La envergadura de la organización y sus objetivos no eran, por otra parte, las únicas coincidencias: la apropiación de ganado y cautivos y la adquisición de mérito militar para lucir eran apreciadas por los miembros de los dos bandos, aunque el peso de la guerra como estrategia de reproducción social no fuera equivalente.

Por fin, la cuestión de los sistemas de autoridad es el eslabón entre la guerra (objeto del último capítulo) y la paz que, en el período considerado cristaliza en la erección de reducciones (objeto del segundo capítulo).

Queda bien demostrado que estas últimas cambian la historia de los indígenas reducidos allí, pero también de los "libres", no tanto menos confiables que los primeros para los españoles. Funcionando como centros logísticos, como resignificados "campamentos base", las reducciones volvieron más cuantiosos y seguros aquellos flujos comerciales existentes desde antiguo. Y, de alguna manera, los abipones utilizaron extorsivamente 
estos dispositivos, ya que ningún tratado de paz pudo evitar la dispersión de los reducidos ni consiguió el utópico objetivo de sedentarizarlos.

Sistemas de autoridad, guerra y paz son entonces los grandes temas de este libro, desarrollados a partir de discusiones teóricas de larga tradición en la disciplina antropológica. Pero lo que coloca al texto entre los buenos libros de historia es la indagación de las coyunturas concretas de conflicto, de los contextos de negociación de las paces y la fundación de reducciones, de las trayectorias de caciques particulares, a más de la presentación de episodios de violencia reconstruidos con minucia. En síntesis, esta etnografía histórica reúne lo mejor de la Historia y de la Antropología. Logra sostener tesis originales trabajando sobre fuentes bastante conocidas (las más importantes de ellas publicadas) y dialogando de manera saludablemente crítica con obras y autores más y menos recientes.

\section{BIBLIOGRAPHY}

Bechis, M. (2008 [1989]). Los lideratos políticos en el área araucano pampeana en el siglo XIX. ¿Autoridad o poder? En M. Bechis, Piezas de etnohistoria del sur sud-americano (pp. 263-296). Madrid: Consejo Superior de Investigaciones Científicas.

Boccara, G. (2007). Los vencedores. Los mapuche en la época colonial. Santiago de Chile: Universidad Católica del Norte/ Universidad de Chile.

Lucaioli, C. (2005). Los grupos abipones hacia mediados del siglo XVIII. Buenos Aires: Sociedad Argentina de Antropología.

Nacuzzi, L. (1998). Identidades impuestas. Buenos Aires: Sociedad Argentina de Antropología.

Paz, C. (2005). El nudo gordiano de las políticas indígenas de los grupos chaqueños. Misiones, misioneros y guerras en la génesis de una sociedad de jefatura, segunda mitad del siglo XVIII. Revista Historia, 9 (1), 35-48.

Saignes, T. (1990) Awa y Karai. Ensayos sobre la frontera chiriguano (Siglos XVI-XX). La Paz: Hisbol.

Susnik, B. (1981). Los aborígenes del Paraguay. Asunción: Museo Etnográfico.

Vitar, B. (2003). Algunas notas sobre las figuras de los líderes chaqueños en las postrimerías del siglo XVIII. En R. Mandrini y C. Paz (Comp.), Las fronteras hispano- criollas del mundo indígena latinoamericano en los siglos XVI-XIX. Tandil: Centro de Estudios de Historia Regional, Universidad Nacional del Sur, Instituto de Estudios Histórico Sociales.

\section{AUTHOR}

\section{JUDITH FARBERMAN}

Universidad Nacional de Quilmes/ Consejo Nacional de Investigaciones Científicas y Técnicas, Argentina. Correo electrónico: jfarberman@unq.edu.ar 